\title{
High-resolution X-ray tomographic workflow to investigate the stress distribution in vitreous enamel steels
}

\author{
Alberto Sensini ${ }^{1}$, Gregorio Pisaneschi ${ }^{1}$, Davide Cocchi ${ }^{2}$, Alexander Kao ${ }^{3}$, Gianluca
}

Tozzi $^{3 *}$, Andrea Zucchelli ${ }^{1,2^{*}}$

1 Advanced Mechanics and Materials - Interdepartmental Center for Industrial Research (CIRI-MAM), Alma Mater Studiorum-University of Bologna, I-40123 Bologna, Italy

2 Department of Industrial Engineering, Alma Mater Studiorum-University of Bologna, I-40131 Bologna, Italy

3 Zeiss Global Centre, School of Mechanical and Design Engineering, University of Portsmouth, Portsmouth PO1 3DJ, United Kingdom

\section{Corresponding authors:}

Andrea Zucchelli

Department of Industrial Engineering

School of Engineering and Architecture

University of Bologna

Viale Risorgimento, 2

40136 Bologna, Italy

e-mail: a.zucchelli@unibo.it

Gianluca Tozzi

Zeiss Global Centre

School of Mechanical and Design Engineering

University of Portsmouth

Anglesea Road

PO2 0JP

Portsmouth, UK

Email: gianluca.tozzi@ port.ac.uk 


\begin{abstract}
Vitreous enamel steels (VES) are a class of metal-ceramic composite materials realized with a low carbon steel basement coated by an enamel layer. During the firing phase to adhere the enamel to the metal, several gas bubbles remain entrapped inside the enamel volume modifying its internal structure. In this work high-resolution X-ray computed tomography (micro-CT) was used to investigate these composite materials. The micro-CT reconstructions enabled a detailed investigation of VES minimizing the metal artifacts. The tomograms were used to develop finite element models (FEM) of VES by means of a representative volume element (RVE) to evaluate the thermal residual stresses caused by the manufacturing process, as well as the effect of the 3D bubbles distribution on the internal stress patterns after the thermic gradient. The promising results from this study have the potential to inform further research on such composite materials by optimizing manufacturing processes for targeted applications.
\end{abstract}

\title{
Keywords
}

Vitreous Enamel Steel; Micro-CT; Porous Materials; Residual Thermal Stress; FEA; RVE. 


\section{Introduction}

Vitreous enamel steels (VES) are a class of metal-ceramic composite materials realized by means of a two stages coating procedure: a first enamel deposition over a metallic surface, and a subsequent firing at high temperature. These coatings have high resistance to chemical corrosion and mechanical wear, which makes them able to prevent impact instability (Ambu et al., 2014; Andrews, 1961; Vargin, 1967; Zucchelli et al., 2010; Zucchelli et al., 2012; Zucchelli et al., 2010). The enamel raw material is made by a mixture of boron-silicate vitreous matrix (frits) and other metal oxides as additives (Andrews, 1961; Scrinzi \& Rossi, 2010; Vargin, 1967; Wratil, 1984). During the firing phase, a functionally graded interface is produced, determining the adhesion between the coating and the substrate (Ambu et al., 2014; Zucchelli et al., 2012). In the process, several gases are released and entrapped into the vitreous matrix in the form of bubbles (Samiee et al., 2008; Yang et al., 2004). The number of bubbles, their dimensions and spatial distribution are fundamental parameters to determine the enamel coating elastic behavior and mechanical strength. Furthermore, during the manufacturing process, residual stresses are introduced. In fact, throughout the cooling phase to room temperature, due to the difference between the linear coefficient of thermal expansion (CTE) of the vitreous enamel material and the metal substrate, a thermal mismatch stress is generated. Such residual stresses affect cracking and spallation of the coating, inducing shape changes that could modify the overall performance of the structure (Ambu et al., 2014). In order to study the residual stress distribution, finite element analysis (FEA) of enamel steel structures has been used (Son et al., 2012, 2014, 2015). In particular Ambu et al. developed a micrographybased finite element model (FEM) to quantify the residual stress distribution on VES sheets, revealing how bubbles have a great influence on residual stress distribution and 
on the mechanical strength of the coating (Ambu et al., 2014). However, the use of 2D imaging techniques could not reliably be used to understand the bubble spatial distribution in the VES volume, and their influence on the enamel coating performance. A possible solution to overcome this limitation, is to produce 3D models based on high-resolution X-ray computed tomography (micro-CT). In a preliminary study, Bernasconi et al. used synchrotron x-ray (voxel size $=9 \mu \mathrm{m})$ to scan glaze slabs deposited on ceramic tiles, showing the internal bubbles distribution (Bernasconi et al., 2012). These results were achieved considering the extremely high resolution of the synchrotron micro-CT, which enabled to resolve both glaze and tile having similar Xray absorption. More recently Van der Linden and co-workers, used two different laboratory micro-CT systems (voxel size $=35 \mu \mathrm{m}$ ) to morphologically analyze different vitreous enamel copper Pyxis and a decorative enameled plate (Van Der Linden et al., 2010). They investigated the internal crack presence and the different layers in the structure. However, due to the low resolution used, they were not able to identify any bubbles in the enamel coating. Moreover, the different x-ray absorption between enamel coating and metal layer (Stock, 2008) makes segmentation and meshing of VES materials extremely challenging to obtain, enhancing the presence of image artifacts.

The idea underpinning the present work was to overcome these limitations, designing a laboratory micro-CT workflow to obtain a detailed distribution of bubbles in the enamel coating. This work has generated subject-specific FEM to investigate both their internal morphology and the residual thermal stress distribution. Different VES samples were imaged, segmented, meshed and finally investigated by using a representative volume element (RVE) based model under a thermal gradient to evaluate the residual stresses. 


\section{Materials and methods}

\section{Materials and samples production}

Three VES samples (manufactured as enamel-steel-enamel) of different compositions, called WL, BL and SM005 respectively, were kindly provided by New Smaltiflex Energia S.r.l. (San Felice sul Panaro, Modena, Italy) and produced as previously described (Zucchelli et al., 2010; Zucchelli et al., 2010). The substrates used for the enamel coating were cold rolled rectangular plates of very low carbon steel (DC04ED) whose chemical composition in wt. $\%$ was as follows: $\mathrm{C}=0.004, \mathrm{~S}=0.015, \mathrm{Mn}=$ $0.22, \mathrm{P}=0.008, \mathrm{Al}=0.037, \mathrm{Ni}=0.036, \mathrm{Cr}=0.021, \mathrm{Cu}=0.032$, and $\mathrm{Fe}$ balance. The dimensions of the steel sheets were $17 \mathrm{~mm} \times 2.5 \mathrm{~mm} \times 0.8 \mathrm{~mm}$. To remove grease and impurities from the metal substrates, they were soaked in a chemical degreasing bath at $70{ }^{\circ} \mathrm{C}$ for $10 \mathrm{~min}$. The degreasing agent was a solution of $5 \%(\mathrm{w} / \mathrm{v})$ commercial sodium hydroxide, benzenesulfonic acid and mono-C10-14 alkyl derivates (MAZZON S.p.A., Vicenza, Italy). To remove rust and to increase the surface roughness, the steel sheets were then pickled in a sulfuric acid solution at $5 \%$ at $65{ }^{\circ} \mathrm{C}$ for $5 \mathrm{~min}$. To increase the iron oxidation, they were immersed in a bath of $1.2 \%(\mathrm{w} / \mathrm{v})$ of sulfate of nickel at $68{ }^{\circ} \mathrm{C}$. This enabled the deposition of a thin layer of nickel on their surfaces. The vitreous enamel slips were produced by milling proper frits, whose chemical composition is reported in Table 1.

Table 1 Chemical composition of enamel frits in wt.\% of oxides.

\begin{tabular}{|c|c|c|c|c|c|c|c|c|c|c|c|c|c|c|c|c|}
\hline & $\mathrm{SiO}_{2}$ & $\mathrm{Al}_{2} \mathrm{O}_{3}$ & $\mathrm{~B}_{2} \mathrm{O}_{3}$ & $\mathrm{~F}_{2}$ & $\mathrm{Na}_{2} \mathrm{O}$ & $\mathrm{K}_{2} \mathrm{O}$ & $\mathrm{P}_{2} \mathrm{O}_{5}$ & $\mathrm{ZnO}$ & $\mathrm{TiO}_{2}$ & $\mathrm{CaO}$ & $\mathrm{MnO}$ & $\mathrm{CoO}$ & $\mathrm{NiO}$ & $\mathrm{CuO}$ & $\mathrm{BaO}$ & $\mathrm{ZrO}_{2}$ \\
\hline WL & 43 & 1 & 13 & 4 & 8 & 5 & 3 & 1 & 22 & - & - & - & - & - & - & - \\
\hline BL & 49 & 9 & 15 & 2 & 14 & 4 & 0.9 & - & - & 3 & 0.9 & 0.6 & 0.9 & 0.7 & - & - \\
\hline SM005 & 58 & - & 10 & 2 & 12 & 5 & - & - & 0.3 & 2 & 1.5 & 1 & 1.2 & 1 & 3 & 3 \\
\hline
\end{tabular}


The frits were ball milled down to $45 \mu \mathrm{m}$ and mixed with additives, clay, salts, quartz and water to form a batch of enamel slip. The enamel slips were applied to the steel sheets by a hand-spraying system. The specific gravity of enameling slip was 1.70 $\mathrm{g} / \mathrm{cm}^{3}$. The enameled samples were then dried in an oven at $120{ }^{\circ} \mathrm{C}$. The firing process, which promotes the bond formation between the steel and the enamel, was performed in an industrial furnace. The firing time was 6 min at $860{ }^{\circ} \mathrm{C}$ followed by air cooling. The thickness of the enamel was about $200 \mu \mathrm{m}$ per side.

To investigate the bubble distribution within the enamel volume and to generate subject-specific 3D FEM models of the VES, micro-CT was carried out (Xradia 520 Versa, Zeiss, CA, USA) applying a LE1 source filter. The VES samples (length $\times$ width $\times$ height $=17 \mathrm{~mm} \times 2.5 \mathrm{~mm} \times 1.5 \mathrm{~mm})($ Fig. 1$)$ were mounted vertically inside the micro-CT and imaged $(60 \mathrm{kV}, 5 \mathrm{~W}, 83 \mu \mathrm{A})$, achieving a voxel size of $1.12 \mu \mathrm{m}$. Projections were collected at rotational steps of $0.11^{\circ}$ over $360^{\circ}$, with $10 \mathrm{sec}$. of exposure time.

All the micro-CT images, were reconstructed using the Scout-and-Scan Reconstructor software (Zeiss, CA, USA), and visualized using XM3DViewer1.2.8 software (Zeiss, CA, USA). 


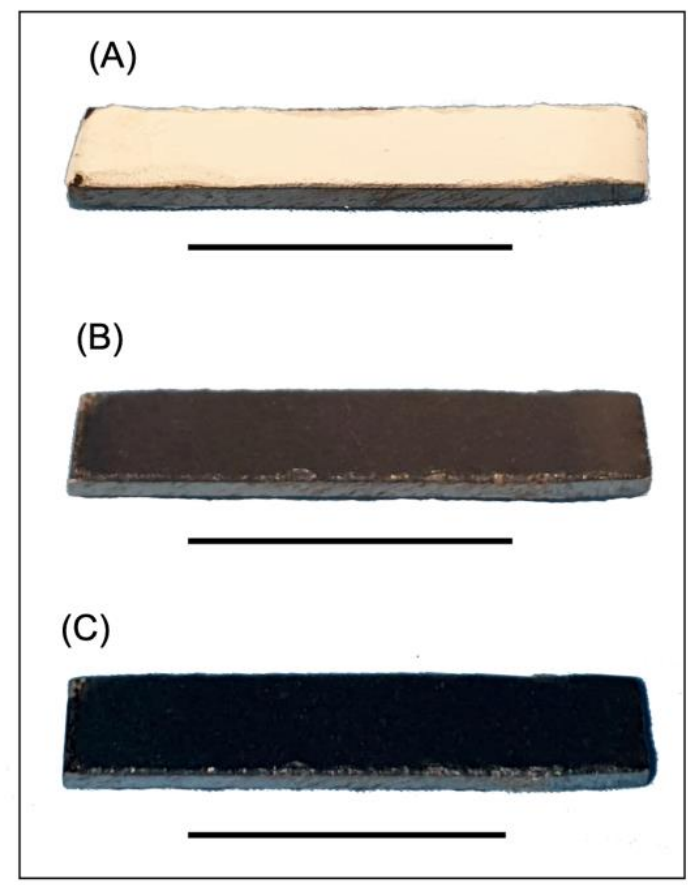

Fig. 1 Prospective views of the VES samples: A) WL; B) BL; C) SM005. The enamel layers were colored white, black and dark blue respectively $($ scale bar $=10 \mathrm{~mm})$.

\section{Preliminary XCT segmentation and surfaces triangulation}

To investigate the residual stress distribution in the enamel coatings, each micro-CT stack was cropped in a sub-volume of 100 slices (length $\times$ width $\times$ height): WL $=180$ $\mu \mathrm{m} \times 112 \mu \mathrm{m} \times 266 \mu \mathrm{m} ; \mathrm{BL}=180 \mu \mathrm{m} \times 112 \mu \mathrm{m} \times 139 \mu \mathrm{m} ; \mathrm{SM} 005=180 \mu \mathrm{m} \times 112$ $\mu \mathrm{m} \times 254 \mu \mathrm{m}$. The steel substrate and their interfaces were masked by using ImageJ (Schneider et al., 2012) (Fig. 2A). A median filter (Fig. 2B) followed by an initial thresholding (Fig. 2C) was applied to each slice to remove the background. Then, the outline of each bubble was manually segmented and the inner part of the bubbles was filled in black to ensure contrast (Fig. 2D). Due to the similarity between the grayscale of the background and the inner part of the bubbles, this manual approach was necessary, as it was not possible to use an automatic segmentation. 


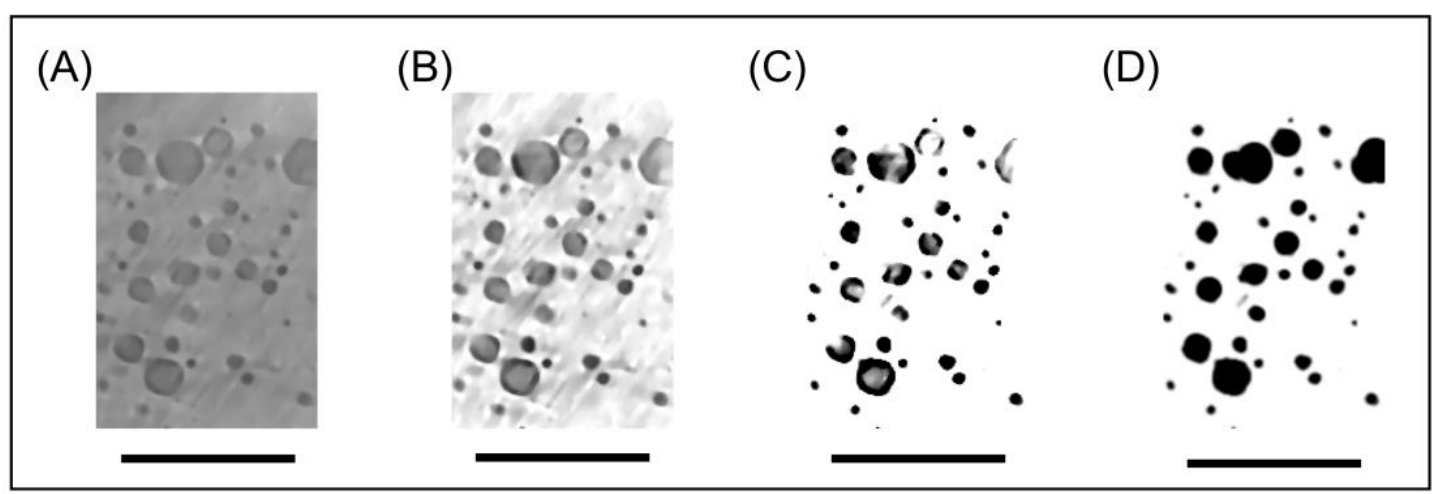

Fig. 2 Preprocessing of a representative micro-CT slice of the BL sample before the segmentation process: A) BL crop as scanned; B) Application of the median filter; C) Preliminary background removal from each slice; D) Manual segmentation of each bubble outline and black filling of the inner part of the bubbles (scale bar $=100 \mu \mathrm{m}$ ).

The resulting masks were then binarized (black bubbles on white background) (Fig. 3A). Subsequently, standard triangulation language (STL) models were obtained from the segmented micro-CT stacks by using MevisLab (Fraunhofer MEVIS, Bremen, Germany) (Fig. 3B). 


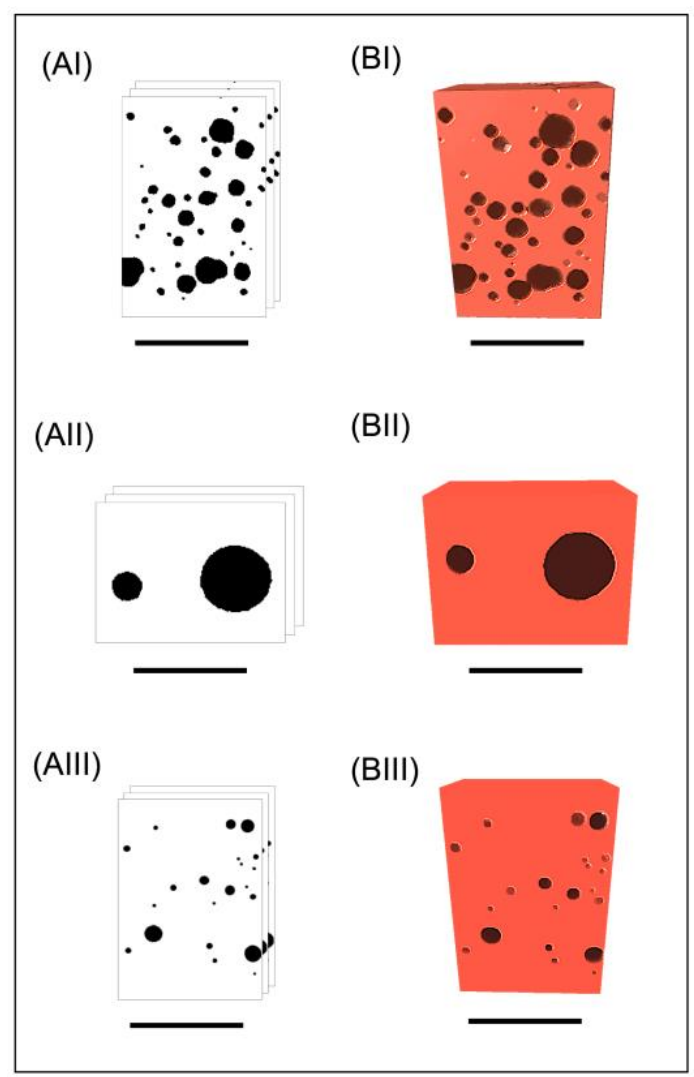

Fig. 3 Segmentation and faceting for the different crops of the VES samples: I) WL; II) BL; III) SM005 (scale bar $=100 \mu \mathrm{m}$ ). A) The XCT stacks were manually segmented. B) The segmented were used to produce STL models.

Volume faceting for FEA

The STL models of VES were then used to generate subject-specific FEM. The crop boundary surfaces were removed, and all the operations were made directly on the bubbles. The faceting, carried out with the 3D modeling software SpaceClaim (ANSYS, Inc., Canonsburg, PA, USA), was necessary to correct the roughness artifacts, due to the micro-CT stacks segmentation and thresholding process (see as example the postprocessing workflow for the SM005 sample in (Fig. 4), making the samples suitable for FEA. Firstly, a smoothing of the original sample (Fig. 4A) was 
performed with the Shrinkwrap facet function of SpaceClaim (Fig. 4B). A comparison between the original SM005 STL model and the smoothed one is shown in (Fig. 4C).

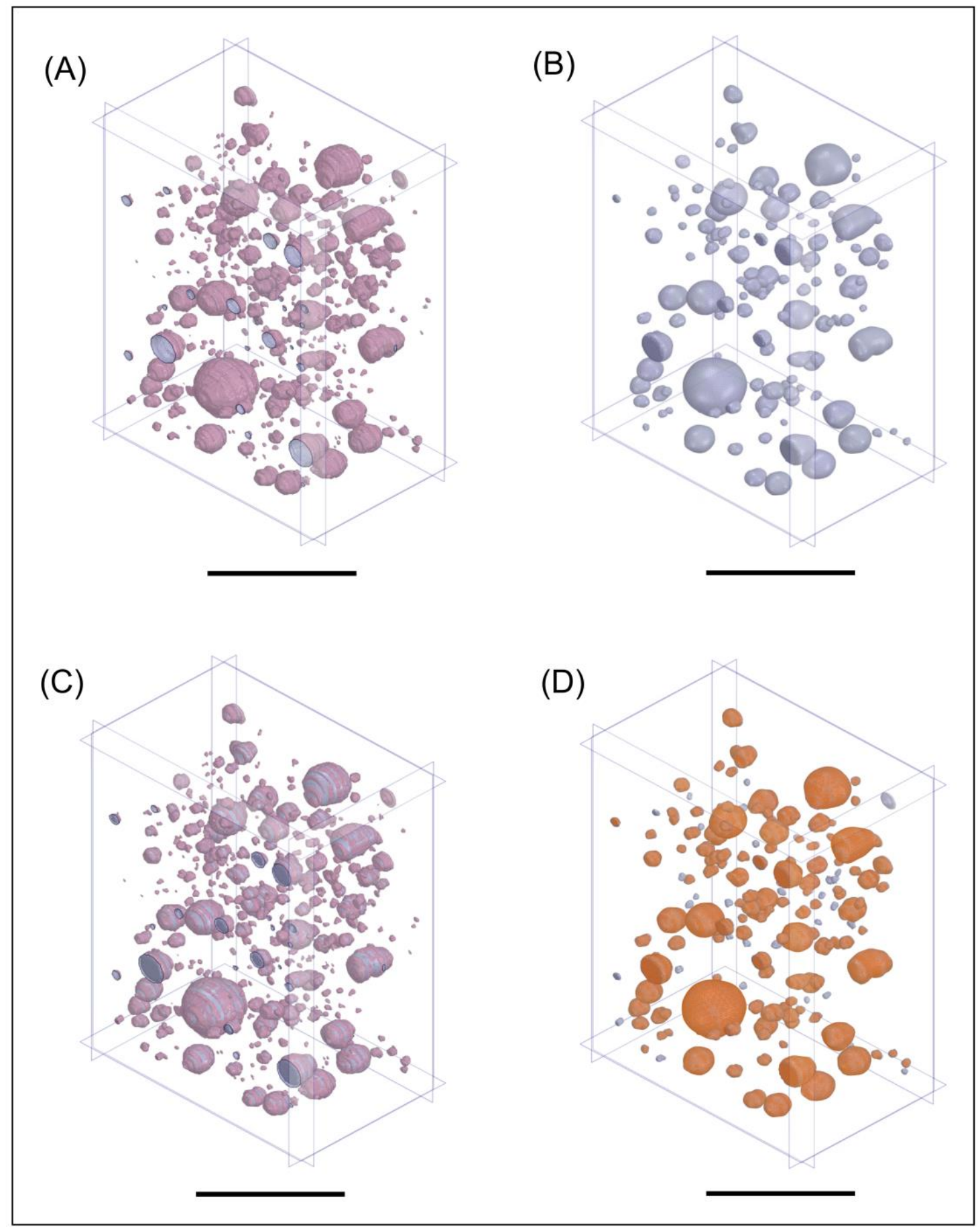

Fig. 4 Representative bubbles postprocessing carried out on the STL models of the VES samples (as example only the SM005 one was reported; scale bar $=100 \mu \mathrm{m}$ ): A) Bubbles from the original STL model; B) Faceting of bubbles to smooth their surfaces; 
C) Overlap of the original bubbles (purple) and the faceted ones (gray); D) Representative figure of the bubbles maintained (orange; diameter $>5 \mu \mathrm{m}$ ) and removed (gray; diameter $<5 \mu \mathrm{m}$ ).

The smallest bubbles, with a mean diameter close to the micro-CT scans voxel size $(1.12 \mu \mathrm{m})$ were considered as noise and erased by the Shrinkwrap function. Secondly, the bubbles with a diameter inferior to $5 \mu \mathrm{m}$, were eliminated. This procedure was necessary, because meshing these bubbles with the required accuracy to obtain a good FEA result, would require a very small element size $(\sim 0.5 \mu \mathrm{m})$, which would increase the computational cost and risk of meshing failure. An exemplificative result is shown in (Fig. 4D), where the orange bubbles are those considered while the gray bubbles were the removed ones. The so treated faceted STL files of the VES bubbles (Fig. 5A), were subtracted to the original filled solidified volume. Finally, any surface defects were removed from the surface of the faceted geometries (Fig. 5B), resulting in a final samples dimensions of (length $\times$ width $\times$ height $): \mathrm{WL}=178 \mu \mathrm{m} \times 110 \mu \mathrm{m} \times 264 \mu \mathrm{m}$; $\mathrm{BL}=178 \mu \mathrm{m} \times 110 \mu \mathrm{m} \times 137 \mu \mathrm{m} ; \mathrm{SM} 005=178 \mu \mathrm{m} \times 110 \mu \mathrm{m} \times 252 \mu \mathrm{m}$. 


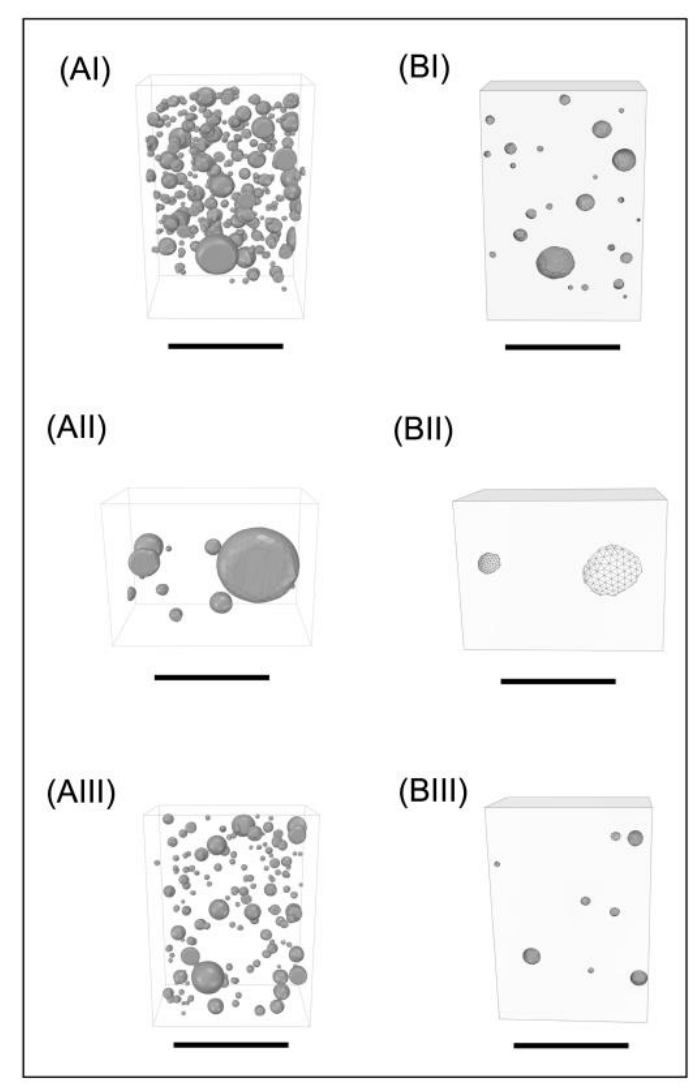

Fig. 5 Bubbles refinement and final geometries for the different VES samples (scale bar $=100 \mu \mathrm{m}$ ): I) WL; II) BL; III) SM005. A) Smoothing of the bubbles after removal the smallest ones. B) Final geometries of the enamel crops for the FEA.

\section{Morphological investigation}

The morphology of bubbles was determined, measuring the total volume of the bubbles from the raw images created with MevisLab and the smoothed samples obtained with SpaceClaim. Thus, the equivalent spherical diameter was calculated for each bubble of the smoothed crop. The best statistical fit of the bubbles diameter distributions was defined with a Kolmogorov-Smirnov test by using EasyFit Professional (MathWave Technologies) software.

\section{Finite element models}


To estimate the residual thermal stress generated during the cooling phase of the coating manufacturing process, a thermal FEA was carried out. The FEM was composed of the vitreous enamel coating and the steel substrate (Fig. 6A). Since the enamel coating is applied on both sides of the steel plate, it is possible to consider only half of the overall thickness reducing the computational time.

For this study, a 3D RVE approach was adopted. An RVE is the smallest material volume element statistically representative of the overall microstructure, morphology and macroscopic constitutive response of the bulk material (Collini et al., 2019; Hill, 1963; Omairey et al., 2019). Such an approach can be adopted for this study because (i) the microstructure is periodic over the enamel deposition surface ( $x$ and $z$ axes of the model, Fig. 6BI, 6BII) and (ii) bubbles within the enamel are randomly distributed. The RVE dimensions must be as small as possible both to reduce the computational time and to better represent the geometrical features (Kanit et al., 2003). The minimum RVE size here adopted was the width of the final VES crops and equal to $110 \mu \mathrm{m}$. This dimension was approximately six times the maximum value among the average bubbles diameters calculated for each sample (i.e. BL mean diameter $=17.47 \mu \mathrm{m}$ ) and enabled providing a significantly representative geometry for the FEM analysis. Concerning the other dimension in plane (i.e. the length), the value of $178 \mu \mathrm{m}$ was maintained, in order not to lose too much information about the microstructure morphology. As a result, the RVE height is half the thickness of the enameled steel sheet, $0.4 \mathrm{~mm}$. Such RVE enabled a periodic representation of the structure of a VES only in the coating deposition plane, as this RVE itself already represented half of the thickness of the overall structure. It is important to notice that the interfaces between the enamel coating and the steel substrate were simplified as flat surfaces. 
The RVE obtained was modelled in ANSYS Workbench (ANSYS, Inc., Canonsburg, PA, USA) using 4 nodes tetragonal elements (Tet4) for the enamel and 8 nodes hexahedral elements (Hex8) for the metal substrate, with an average element size of 2 $\mu \mathrm{m}$ and $4 \mu \mathrm{m}$, respectively (Fig. 6BI, 6BII). Both the composition of enamel and metal substrate were assumed homogeneous, the behavior isotropic and an elastic linear law was used. The values of the linear CTE $\left(\alpha_{\mathrm{L}}\right)$, the elastic modulus $(\mathrm{E})$ and the Poisson coefficient $(v)$, given by the material producer (New Smaltiflex Energia S.r.l., San Felice sul Panaro, Modena, Italy), are listed in Table 2.

Table 2 Physical and mechanical properties of the different constituent materials.

\begin{tabular}{lccc}
\hline Material & $\begin{array}{c}\alpha_{\mathrm{L}} \\
\left(10^{-5}{ }^{\circ} \mathrm{C}^{-1}\right)\end{array}$ & $\begin{array}{c}\mathrm{E} \\
(\mathrm{MPa})\end{array}$ & $\begin{array}{c}v \\
(-)\end{array}$ \\
\hline DC04ED & 1.30 & 180000 & 0.30 \\
WL & 1.21 & 70000 & 0.28 \\
BL & 1.25 & 65000 & 0.28 \\
SM005 & 1.16 & 74000 & 0.28 \\
\hline
\end{tabular}

(A)


Fig. 6 RVE approach applied on the samples for the FEA (SM005 sample is reported; scale bar $=100 \mu \mathrm{m})$ : A) RVE model including the enamel and steel substrate. B) RVE mesh: BI) overview; BII) zoom in. C) RVE boundary conditions.

FEM simulations were carried out by imposing a homogeneous thermal gradient under periodic boundary conditions (PBCs). PBCs are necessary to simulate the deformation of the material surrounding the RVE, ensuring that the external surfaces of the RVE remain periodic (Omairey et al., 2019). In this case, the periodicity of the RVE was represented by imposing boundary conditions that keep the outer surfaces of the RVE planar during the deformation, except for the enamel surface, that could deform freely. This was done by using Remote Point feature of ANSYS software, which facilitates controlling the degrees of freedom (DOFs) of the boundary nodes in the RVE model. For the remaining three surfaces of the RVE, the normal displacement was constrained to define a reference orthogonal system. The model geometry, mesh, and PBCs conditions are represented in (Fig. 6C) for the SM005 sample.

For each RVE model, the enamel manufacturing process was then simulated by imposing a homogeneous linear thermal gradient of $400{ }^{\circ} \mathrm{C}$, starting from $425^{\circ} \mathrm{C}$ up to room temperature.

\section{Results}

Micro-CT of VES samples

The results from the micro-CT of VES are showed in (Fig. 7). The structure and internal bubbles of the vitreous enamel coatings were clearly visualized, as well as the steel substrate and the interface region between the two materials. 


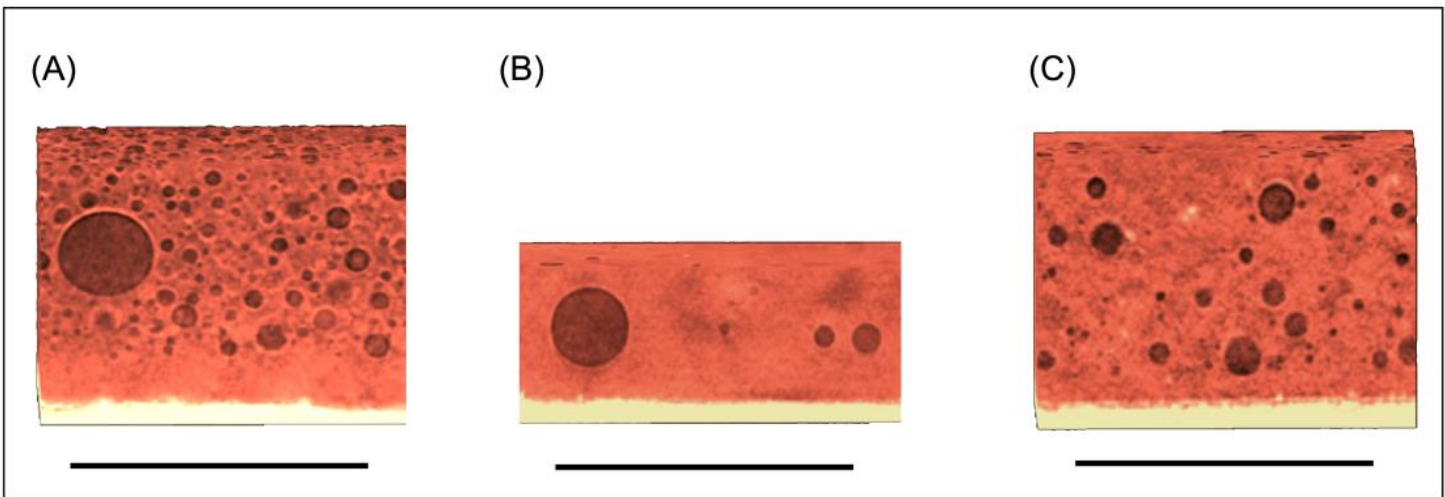

Fig. 7 XCT scans overview of the VES samples composed by the enamel (red) and the steel basement (yellow) (scale bar $=300 \mu \mathrm{m})$ : A) WL; B) BL; C) SM005.

\section{Morphology of the VES bubbles}

The morphological results are listed in Table 3, including the raw samples (MevisLab) and the smoothed ones (SpaceClaim).

Table 3 Comparison between the bubbles number and volume respect to the enamel total volume for the raw and the smoothed versions of the VES samples.

\begin{tabular}{lcccccc}
\cline { 2 - 5 } & \multicolumn{3}{c}{ Raw Version } & \multicolumn{3}{c}{ Smoothed Version } \\
\hline $\begin{array}{c}\text { Bubbles } \\
(-)\end{array}$ & $\begin{array}{c}\text { Enamel Total } \\
\text { Volume } \\
\left(\mu \mathrm{m}^{3}\right)\end{array}$ & $\begin{array}{c}\text { Mean Bubbles } \\
\text { Volume } \\
\left(\mu \mathrm{m}^{3}\right)\end{array}$ & $\begin{array}{c}\text { Bubbles } \\
\text { Number } \\
(-)\end{array}$ & $\begin{array}{c}\text { Enamel Total } \\
\text { Volume } \\
\left(\mu \mathrm{m}^{3}\right)\end{array}$ & $\begin{array}{c}\text { Mean Bubbles } \\
\text { Volume } \\
\left(\mu \mathrm{m}^{3}\right)\end{array}$ \\
\hline WL & 463 & 453011 & 978 & 263 & 391850 & 1490 \\
BL & 23 & 281417 & 12236 & 14 & 275085 & 19649 \\
SM005 & 180 & 204576 & 1137 & 125 & 179242 & 1434 \\
\hline
\end{tabular}

The number of bubbles was almost halved in the smoothed version, since there were many small ones. For this reason, an increase in the mean bubble volume was observed as a result of the smoothing, despite the smoothing with the Shrinkwrap function slightly reduced their volume (Fig. 4C) due to the removal of the smallest ones. The VESs porosity percentages before Shrinkwrap were $\mathrm{WL}=8.86 \%, \mathrm{BL}=10.47 \%$ and 
SM005 $=4.18 \%$, while after smoothing were $\mathrm{WL}=7.66 \%, \mathrm{BL}=10.24 \%$ and $\mathrm{SM} 005$ $=3.66 \%$.

The diameter of every bubble of the smoothed sample was measured. The statistical results for each sample are reported in Table 4.

Table 4 Comparison between the bubbles diameter of the smoothed samples.

\begin{tabular}{lcccc}
\hline & $\begin{array}{c}\text { Mean } \\
\text { Diameter } \\
(\mu \mathrm{m})\end{array}$ & $\begin{array}{c}\text { Standard } \\
\text { Deviation } \\
(\mu \mathrm{m})\end{array}$ & $\begin{array}{c}\text { Maximum } \\
\text { Diameter } \\
(\mu \mathrm{m})\end{array}$ & $\begin{array}{c}\text { Minimum } \\
\text { Diameter } \\
(\mu \mathrm{m})\end{array}$ \\
\hline WL & 10.08 & 5.39 & 44.79 & 3.66 \\
BL & 17.47 & 17.17 & 70.48 & 5.14 \\
SM005 & 10.06 & 5.36 & 37.91 & 4.71 \\
\hline
\end{tabular}

The results were similar for WL and SM005, while consistently different compared to BL. The bubbles diameter distribution for each sample (Fig. 8) was best fitted by a lognormal 3-parameter distribution, typically found in porous solids. The fitting parameters for the different VES were: WL $(\sigma=0.772 ; \mu=1.63 ; \gamma=3.29)$, BL $(\sigma=$ $1.54 ; \mu=1.63 ; \gamma=4.96), \operatorname{SM} 005(\sigma=0.949 ; \mu=1.31 ; \gamma=4.46)$. In particular, $\sigma$ is the shape parameter (i.e. the standard deviation of the $\log$ of the distribution), $\mu$ is the scale parameter (i.e. the median of the distribution) and $\gamma$ is the location parameter. 


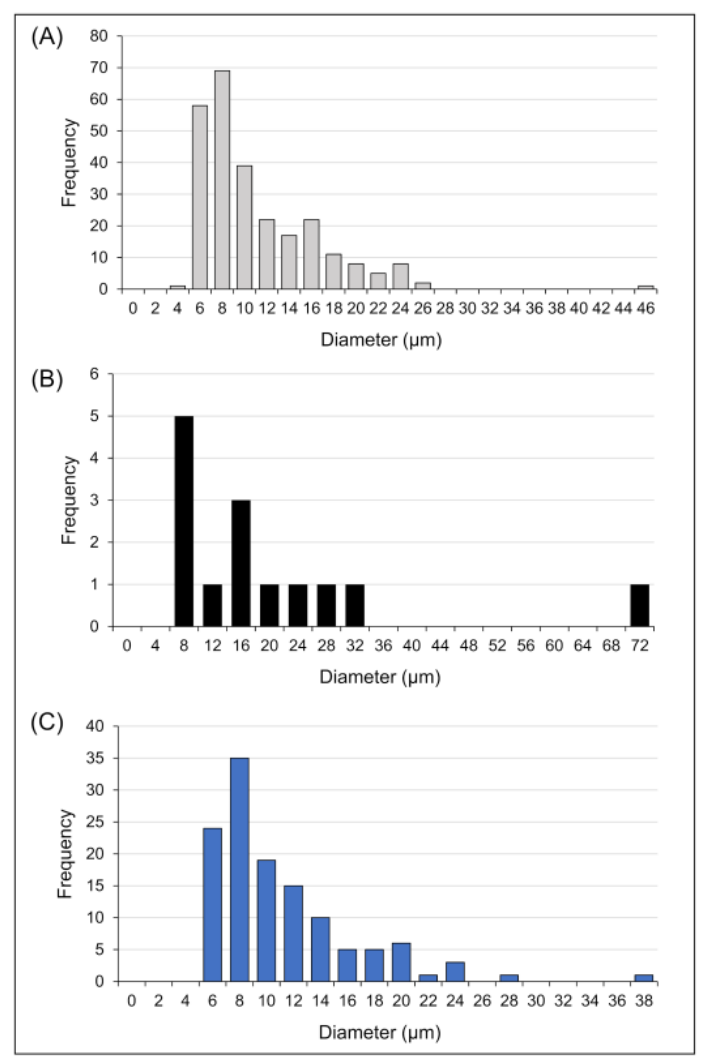

Fig. 8 Histograms of the bubbles diameter distribution for each smoothed VES sample represented as frequency for each diameter range: A) WL; B) BL; C) SM005.

\section{FEM simulations}

The thermal FEM simulation of the VES cooling process enabled the evaluation of the residual thermal stresses generated both in the enamel and steel substrate. For this purpose, the equivalent Von Mises stress $\left(\sigma_{\text {eq }}\right)$ and the normal stresses along $x$ and $z$ axes ( $\sigma_{x}$ and $\sigma_{z}$ respectively, i.e. in the enamel deposition plane) were computed, since the RVE can deform freely in the $y$-direction. The 3D distributions of $\sigma_{\mathrm{eq}}, \sigma_{\mathrm{x}}$ and $\sigma_{\mathrm{z}}$ at the end of the cooling process for the three types of enamel in the sectioned RVEs are reported in Fig. 9. 


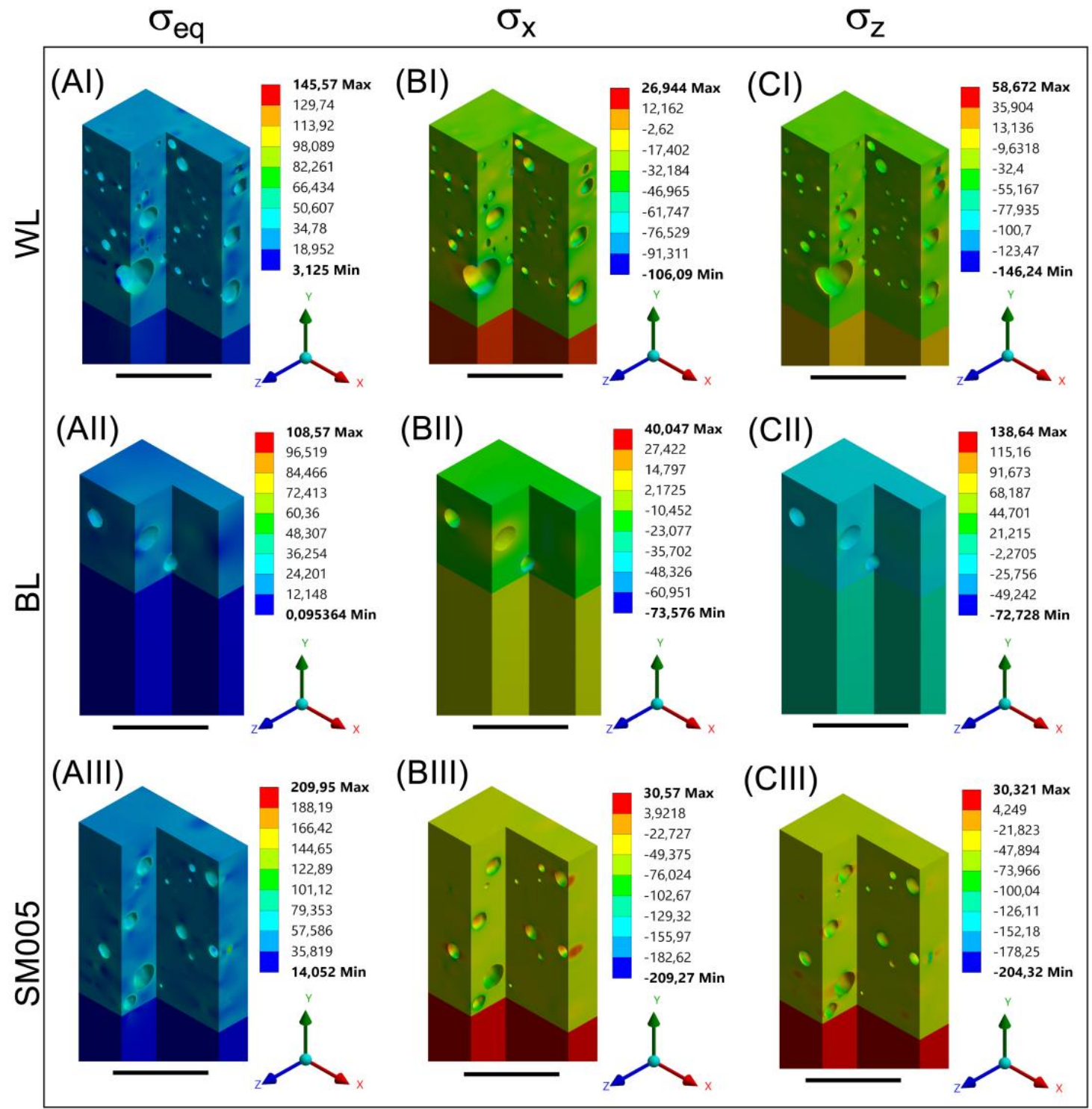

Fig. 9 VES stress distribution in the sectioned RVEs obtained from the cooling phase FEM simulation for: I) WL, II) BL and III) SM005 samples (scale bar $=100 \mu \mathrm{m})$. A) Equivalent Von Mises stress $\left(\sigma_{\mathrm{eq}}\right)$. B) Normal stress along $x$ axis $\left(\sigma_{\mathrm{x}}\right)$. C) Normal stress along $z$ axis $\left(\sigma_{z}\right)$.

For all samples it was found that at room temperature the metal substrate was subjected to residual tensile stresses along both the $x$ and $z$ axis, while the enamel showed residual compressive stresses. 
The Von Mises stress distribution for an internal cross section in the enamel (Fig. 10AI-CI) is showing high stress values, particularly on the bubbles linking direction. The frictional stress patterns at the interface between the enamel and the steel substrate (Fig. 10AII-CII) are negligible compared to the values found in the entire RVE (Fig. 9), since here the stress changed from tensile to compressive at the interface.

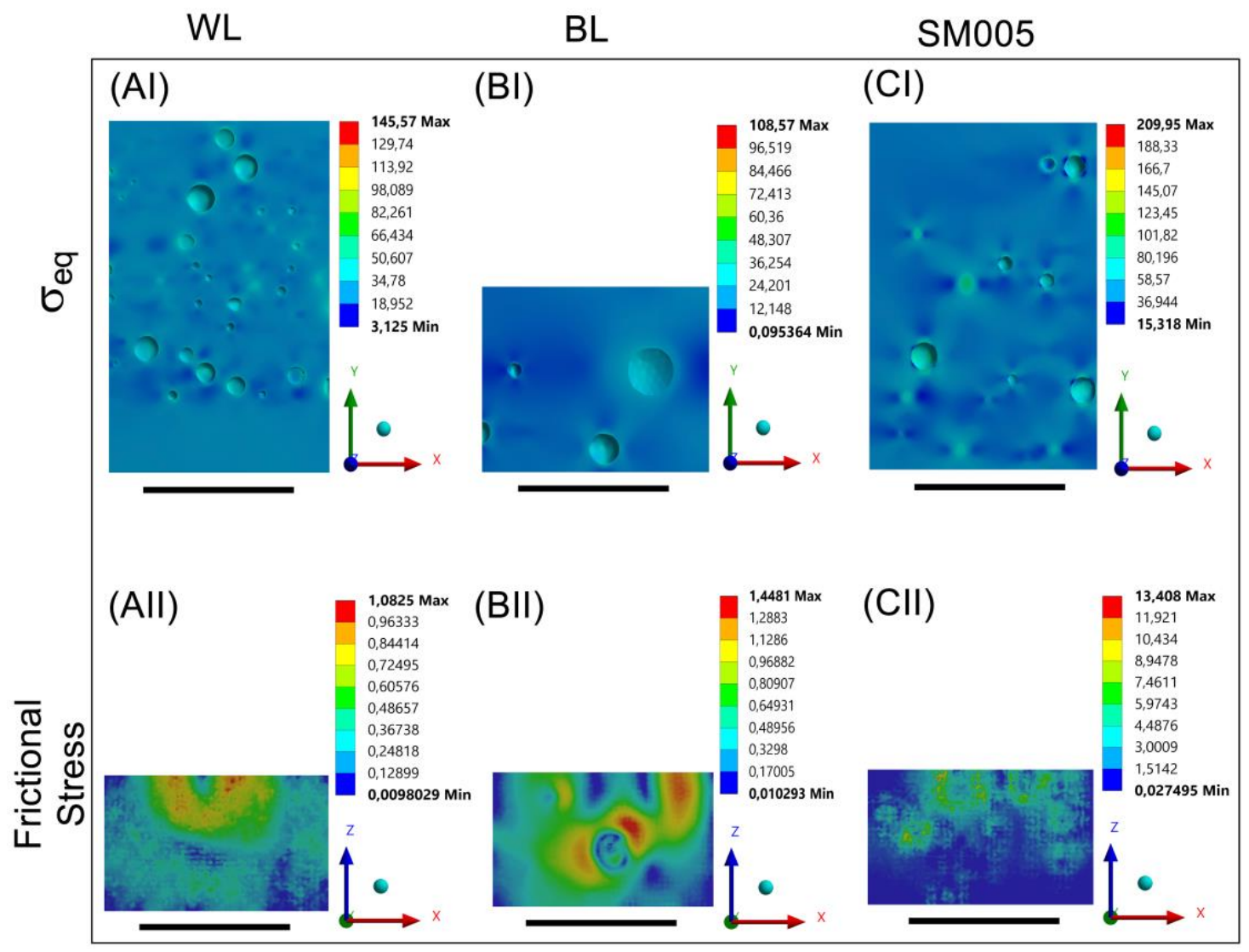

Fig. $102 \mathrm{D}$ cross sectional stress patterns inside the enamel and at the enamel-steel interface for: A) WL, B) BL and C) SM005 samples (scale bar $=100 \mu \mathrm{m}$ ). I) Equivalent Von Mises stress and II) Frictional stress distribution.

\section{Discussion}

The VES morphological and thermomechanical investigation is complex due to the impossibility so far to estimate their real volume and internal microstructure. This is a 
huge limitation as gas bubbles, entrapped inside the VES volume during the firing phase, strongly modify their overall structure and the residual stress distribution throughout the cooling phase. Previous research studied the bubbles mechanical influence by using micrography-based 2D FEMs (Ambu et al., 2014), locally verifying how the bubbles shape could guide the stress distribution inside VES. In this work, the mechanical modelling of VES properties was upgraded by using the micro-CT-based FEA, in order to investigate the full volume of the samples. The micro-CT of the enamel-steel interface of VES (Fig. 7), with unpreceded resolution $(1.12 \mu \mathrm{m})$ compared to the previous literature in the ceramic research field (Bernasconi et al., 2012; Van Der Linden et al., 2010), guaranteed an accurate description of the bubbles morphology and distribution as well as generation of a FEM of the entire VES.

The mean diameters of the bubbles for each VES were successfully evaluated both in the raw and the smoothed 3D reconstructions. Despite the removal of the smallest bubbles (volume $<50 \mu \mathrm{m}^{3}$ ), that were approximately $1 / 3$ of their total number for each VES, the bubble volume differences between the raw and smoothed versions were minimal $(\mathrm{WL}=13.5 \% ; \mathrm{BL}=2.3 \% ;$ SM005 $=12.4 \%)$. Moreover, this XCT-based method to evaluate the VES bubbles mean diameter takes into account the 3D volume, thus reducing approximations caused by the $2 \mathrm{D}$ estimation.

FEA results at the end of the cooling phase showed how residual thermal stresses are compressive for the enamel coatings, while tensile for the steel substrates (Fig. 9). This is related to the difference in the linear CTE between the enamel and the metal substrate. As in Table 2, the linear CTE value for steel is higher than that for enamels. This means that under the same thermal gradient, the steel deformation is greater than 
that of the enamel, thus generating residual tensile stresses in the steel and compressive in the enamel layer.

Observing the equivalent stress distribution both in the 3D representations (Fig. 9AIAIII) and in particular in the section side views (Fig. 10AI-CI), it is interesting to note how the stress concentrations are found in the enamel and in particular on the bubbles linking direction. This effect, widely reported in literature (Boccaccini et al., 1996; Peterson, 1965; Peterson, 1974; Pilkey \& Pilkey, 2008) is particularly evident in regions with higher porosity volume fraction, due to the bubble-stress interaction (Rice, 1997). It has been demonstrated that the thermomechanical properties of porous materials (to which VESs belong to) are directly related to the porosity percentage. In fact, as the latter increases, the stress shielding effect is emphasized but simultaneously a reduction in the load-bearing area occurs (Boccaccini, 1998; Rice, 1997; Salvini et al., 2018). In the present study, it was difficult to make a qualitative comparison among the thermomechanical properties of the three different samples as the enamel thicknesses were different (due to the hand-made spraying process), and consequently the residual stress values generated during the cooling phase. However, it is possible to make some quantitative comments. It is interesting to observe how the higher the porosity volume fraction $(\mathrm{BL}=10.24 \%, \mathrm{WL}=7.66 \%$ and $\mathrm{SM} 005=3.66 \%$, after crop smoothing) lowered the maximum equivalent stress value $(\mathrm{BL}=108.57 \mathrm{MPa}, \mathrm{WL}=$ 145.57 MPa and SM005 = 209.95 MPa). In fact, it has been shown that at increasing porosity volume fractions, the stress concentration values are reduced due to interactions between the pores as the interstitial spaces (Rice, 1997).

It is worth mentioning that the maximum and minimum values of the normal stresses along $x$ and $z$ axes $\left(\sigma_{\mathrm{x}}\right.$ and $\sigma_{\mathrm{z}}$, respectively (Fig. 9)) are almost the same for the SM005 
sample $\left(\sigma_{x, z} \min =-209.27 \mathrm{MPa}\right.$ and $\left.\sigma_{x, z} \max =30.57 \mathrm{MPa}\right)$, while there is a substantial difference in the behavior along the same directions for WL and BL samples. This clearly suggests an anisotropic behavior of these two samples, although, in the FEM simulations, the materials were assumed to be isotropic. This was probably due not only to the porosity percentage but above all to the size of the RVEs herein adopted, which might be too small compared to the size of the bubbles. However, as explained, the RVEs dimensions are dependent on the size of the micro-CT images. In addition, shape (i.e. the axial ratio), distribution, and orientation of the spheroidal pores can also affect the thermomechanical behavior of porous materials (Boccaccini, 1999; Chiang, 2015).

The stress values at the enamel-steel interface for each VES (Fig. 10AII-CII) were almost null, since the stress changed from tensile to compressive passing from the enamel to the steel substrate. This behavior was probably caused by approximation of the interface region between the enamel coating and the steel basement to a flat surface. In fact, the real interface has a rough morphology and a different chemical composition along its thickness (Zucchelli et al., 2010). However, this FEM analysis accurately evaluates the stress distribution in the VES volume, underlining the effects caused by the bubbles morphology and their distribution, upgrading the previous literature in the field (Ambu et al., 2014).

\section{Conclusion}

In this study a high-resolution X-ray computed tomography (micro-CT) was used to image vitreous enameled steels. The micro-CT facilitated a clear visualization of both the enamel coating and the metal basement minimizing image artefacts. The postprocessing carried out on the micro-CT images enabled a morphological investigation 
of the gas bubbles entrapped inside the VES volume. A thermal micro-CT-based finite element analysis of Representative Volume Elements (RVEs) provided a better understanding of how the bubble presence and distribution affected the stress distributions inside the volumes. Furthermore, this study opens the way for future in situ investigations of VES by means of digital volume correlation. The results from this study will inform further research on such composite materials by optimizing manufacturing processes for targeted applications.

\section{Acknowledgments}

The Marco Polo Grant of the University of Bologna is greatly acknowledged for the funds for Alberto Sensini's permanence at the University of Portsmouth. New Smaltiflex Energia s.r.l. is greatly acknowledged for the vitreous enamel steels production. The Zeiss Global Centre of the University of Portsmouth is greatly acknowledged for providing micro-CT imaging and image post-processing.

\section{References}

Ambu, R., Zucchelli, A., \& Minak, G. (2014). Residual Stress Evaluation in Vitreous Enameled Steel Sheets by Digital Images Analysis of Microstructures. In F. Rodrigues Leta (Ed.), Visual Computing: Scientific Visualization and Imaging Systems (pp. 171188). Springer.

Andrews, A. I. (1961). Porcelain Enamels (Second Ed). Garrard Press: Champaign.

Bernasconi, A., Diella, V., Marinoni, N., Pavese, A., \& Francescon, F. (2012). Influence of composition on some industrially relevant properties of traditional 
sanitary-ware glaze. Ceramics International, 38(7), 5859-5870. https://doi.org/10.1016/j.ceramint.2012.04.037

Boccaccini, A. R. (1998). Influence of stress concentrations on the mechanical property-porosity correlation in porous materials. Journal of Materials Science Letters. https://doi.org/10.1023/A:1006503524162

Boccaccini, A. R., Ondracek, G., \& Mombello, E. (1996). Determination of stress concentration factors in porous materials. Journal of Materials Science Letters, 15(6), 534-536. https://doi.org/10.1007/bf00275423

Boccaccini, Aldo R. (1999). Fabrication, microstructural characterisation and mechanical properties of glass compacts containing controlled porosity of spheroidal shape. Journal of Porous Materials. https://doi.org/10.1023/A:1009673814848

Chiang, C. R. (2015). Stress concentration around a triaxial ellipsoidal cavity in transversely isotropic materials. Archive of Applied Mechanics. https://doi.org/10.1007/s00419-014-0923-1

Collini, L., Moroni, F., \& Pirondi, A. (2019). Modeling the influence of stress triaxiality on the failure strain of nodular cast iron microstructures. Procedia Structural Integrity, 18, 671-687. https://doi.org/10.1016/j.prostr.2019.08.215

Hill, R. (1963). Elastic properties of reinforced solids: Some theoretical principles. Journal of the Mechanics and Physics of Solids, 11(5), 357-372. https://doi.org/10.1016/0022-5096(63)90036-X

Kanit, T., Forest, S., Galliet, I., Mounoury, V., \& Jeulin, D. (2003). Determination of the size of the representative volume element for random composites: Statistical and 
numerical approach. International Journal of Solids and Structures, 40(13-14), 36473679. https://doi.org/10.1016/S0020-7683(03)00143-4

Omairey, S. L., Dunning, P. D., \& Sriramula, S. (2019). Development of an ABAQUS plugin tool for periodic RVE homogenisation. Engineering with Computers, 35(2), 567-577. https://doi.org/10.1007/s00366-018-0616-4

Peterson, R. E. (1965). The interaction effect of neighboring holes or cavities, with particular reference to pressure vessels and rocket cases. Journal of Fluids Engineering, Transactions of the ASME. https://doi.org/10.1115/1.3650834

Peterson, Rudolph Earl. (1974). Stress Concentration Factors (Rudolph Earl Peterson (ed.)). John Wiley \& Sons.

Pilkey, W. D., \& Pilkey, D. F. (2008). Shoulder Fillets. In W. D. Pilkey \& D. F. Pilkey (Eds.), Peterson's Stress Concentration Factors (Third). John Wiley \& Sons. https://doi.org/10.1002/9780470211106.ch3

Rice, R. W. (1997). Limitations of pore-stress concentrations on the mechanical properties of porous materials. Journal of Materials Science. https://doi.org/10.1023/A:1018674713006

Salvini, V. R., Pandolfelli, V. C., \& Spinelli, D. (2018). Mechanical Properties of Porous Ceramics. In Recent Advances in Porous Ceramics. https://doi.org/10.5772/intechopen.71612

Samiee, L., Sarpoolaky, H., \& Mirhabibi, A. (2008). Influence of bubble structure on adherence and chemical durability of porcelain enamel. Advances in Applied Ceramics, 107(1), 27-33. https://doi.org/10.1179/174367607X202654 
Schneider, C. A., Rasband, W. S., \& Eliceiri, K. W. (2012). NIH Image to ImageJ: 25 years of image analysis. Nature Methods, 9(7), 671-675. https://doi.org/10.1038/nmeth.2089

Scrinzi, E., \& Rossi, S. (2010). The aesthetic and functional properties of enamel coatings on steel. Materials and Design, 31(9), 4138-4146. https://doi.org/10.1016/j.matdes.2010.04.030

Son, Y. K., Lee, C. J., Lee, J. M., \& Kim, B. M. (2012). Deformation prediction of porcelain-enameled steels with strain history by press forming and high-temperature behavior of coating layer. Transactions of Nonferrous Metals Society of China (English Edition), 22(SUPPL.3), 838-844. https://doi.org/10.1016/S1003$6326(12) 61813-5$

Son, Y. K., Lee, K. H., Yang, K. S., Ko, D. C., \& Kim, B. M. (2015). Prediction of residual stress and deformation of enameled steel. International Journal of Precision Engineering and Manufacturing, 16(7), 1647-1653. https://doi.org/10.1007/s12541015-0216-9

Son, Y. K., Zhao, Y. L., Ko, D. C., \& Kim, B. M. (2014). Prediction of cracking initiation in enamel coated product and its verification by four-point bending test. Journal of Mechanical Science and Technology, 28(4), 1481-1489. https://doi.org/10.1007/s12206-014-0134-2

Stock, S. R. (2008). MicroComputed Tomography: Methodology and Applications (S. R. Stock (ed.); First). Taylor \& Francis Group. https://doi.org/https://doi.org/10.1201/9781420058772 
Van Der Linden, V., Van De Casteele, E., Thomas, M. S., De Vos, A., Janssen, E., \& Janssens, K. (2010). Analysis of micro computed tomography images; A look inside historic enamelled metal objects. Applied Physics A: Materials Science and Processing, 98(2), 385-392. https://doi.org/10.1007/s00339-009-5394-9

Vargin, V. V. (1967). Technology of Enamels. Maclaren and Sons.

Wratil, J. (1984). Vitreous Enamel. Borax Holding Limited.

Yang, X., Jha, A., Brydson, R., \& Cochrane, R. C. (2004). The effects of a nickel oxide precoat on the gas bubble structures and fish-scaling resistance in vitreous enamels. Materials Science and Engineering A, 366(2), 254-261. https://doi.org/10.1016/j.msea.2003.08.003

Zucchelli, A., Dignatici, M., Montorsi, M., Carlotti, R., \& Siligardi, C. (2012). Characterization of vitreous enamel-steel interface by using hot stage ESEM and nanoindentation techniques. Journal of the European Ceramic Society, 32(10), 2243-2251. https://doi.org/10.1016/j.jeurceramsoc.2012.03.008

Zucchelli, A., Minak, G., \& Ghelli, D. (2010). A particular instability of unilaterally supported thin plates under transversal load: Effect of the residual stresses induced by vitreous enameling. Strain, 46(5), 419-434. https://doi.org/10.1111/j.14751305.2009.00675.x

Zucchelli, Andrea, Minak, G., \& Ghelli, D. (2010). Low-velocity impact behavior of vitreous-enameled steel plates. International Journal of Impact Engineering, 37(6), 673-684. https://doi.org/10.1016/j.ijimpeng.2009.12.003 